\title{
Bigger, Better, Stronger, Faster: should we join them or go it alone?
}

It seems our journal is moving on so well that there are other parties who would like to join us. I have had requests motivating to have a section of the journal dedicated to a specific discipline. The first of these is Medical Oncology, who have funding, a high-profile experienced scientific editorial team and who are extremely interested. Other parties to consider within Radiation Science are nuclear medicine physicians, radiographers, radiation physicists and radiation biologists.

The benefits would be a stronger, richer and more diverse journal with a wider readership. The longevity and interest in the journal would be extended and we would bring our colleagues closer to us. This is a natural grouping of specialties associated with radiation and imaging under the banner of Radiology (as this is the name of the existing journal).

This is a proposal which we must consider. Added to this is the possibility of representing Africa. Movements are under way under the auspices of the ISR (International Society of Radiology) to form an African Society of Radiology. We want to play a large leadership role here and offering our journal to represent the whole of Africa is a vision that should be high on the agenda.

I am in favour of change towards a stronger, wider group representing all of Africa; within this I will endeavour to retain our identity and influence by striving for excellence and productivity in research.

Medline/Pubmed (NLM) accreditation is the Holy Grail of a journal. I have applied on our behalf and I am awaiting a response.

Please contact me via email at docsav@mweb.co.za for comments good or bad, as I may have overlooked something in my overeager response.

\section{Savvas Andronikou}

Chief Editor 